\title{
BIODIVERSITY OF MICROFUNGI IN SOILS, PLANT ROOTS AND FOODS: A COMPARISON BETWEEN ORGANIC AND CONVENTIONAL AGRICULTURAL ECOSYSTEMS
}

\author{
N.W. WAIPARA ${ }^{1}$ and M. TORP ${ }^{2}$ \\ ${ }^{I}$ New Zealand Pastoral Agricultural Research Institute Ltd., Ruakura Research Centre, Private Bag \\ 3123, Hamilton, New Zealand \\ ${ }^{2}$ National Veterinary Institute Pb 8156, Dep0033, Oslo, Norway
}

\begin{abstract}
Microbiological surveys of soils, plant roots and fruit and vegetable produce, have shown the biomass and biodiversity of microfungi obtained from organically cultivated soils, plant roots and organically produced fruit and vegetables can be distinct to that obtained from conventional agriculture and food production. Microbial biomass was observed to be numerically larger and species richness greater in cultivated organic soils. The number of microfungi isolated from plant roots in organic cultivation was similar to that recovered in conventional samples, however, species biodiversity was greater in organic samples. Organic soils had proportionally higher numbers of potentially beneficial species, such as the nematode suppressive fungus Paecilomyces lilacinus, and a lower number of deleterious soilborne plant-pathogenic species present. Biodiversity of microfungi was also greater on all organic produce tested. Potential food spoilage and toxin producing genera were more commonly isolated from conventional fruit and vegetable samples than organic samples. Therefore the contribution of microfungi to soil health in organic agricultural ecosystems may be greater than that found in other agricultural ecosystems.
\end{abstract}

\section{INCIDENCE OF ONION NECK ROT IN CANTERBURY}

\section{S.L.H. VILJANEN-ROLLINSON and S.K. HALSE}

\author{
New Zealand Institute for Crop \& Food Research Limited, Private Bag 4704, Christchurch
}

Onion neck rot (caused by Botrytis allii Munn.) can cause up to $60 \%$ losses of stored bulbs. Field trials were carried out to assess the effect of cropping history (onions grown the previous season or onions grown more than 4 years previously), fungicide treatment (no fungicide or calendar spraying of fungicides) and the amount of infection in the seed (Botrytis-free seed or $40 \%$ of seed infected) on neck rot infections in 1998/1999. Disease levels measured from senesced leaves and stored bulbs were extremely low. A total of 26 leaves out of 5280 leaves sampled produced colonies of B. allii, 20 of these were in paddocks in which onions had been grown previously. A total of 32 bulbs had internal $B$. allii infection and 22 of these were in the paddock in which onions had been grown in the previous season. During the 1999-2000 season, field plots were inoculated with B. allii conidia or treated with fungicide. More disease was found in inoculated plots than from fungicide treated plots when averaged over all sampling dates. Weather conditions at the time of harvest are probably the major factor determining whether a particular crop will develop the disease or not. 